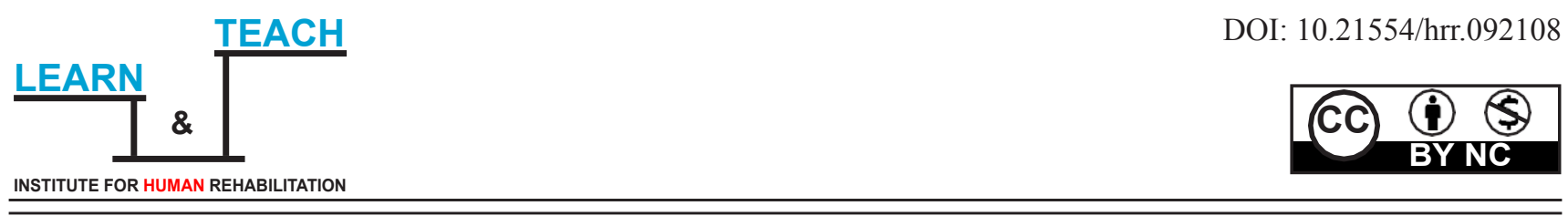

\title{
CORRELATION BETWEEN PURE TONE THRESHOLDS AND SPEECH THRESHOLDS
}

Original scientific paper

\author{
Lidija Ristovska $^{1}$, Zora Jachova ${ }^{2}$ Jasmina Kovacevic $^{3}$, Vesna Radovanovic ${ }^{3}$, Husnija Hasanbegovic ${ }^{4}$ \\ ${ }^{1}$ City General Hospital " $8^{\text {th }}$ September”, Department of Otorhinolaryngology, Division of Audiology, Skopje, North Macedonia \\ ${ }^{2}$ Ss. Cyril and Methodius University in Skopje, Faculty of Philosophy, Institute of Special Education and Rehabilitation, \\ Skopje, North Macedonia \\ ${ }^{3}$ University of Belgrade, Faculty of Special Education and Rehabilitation, Belgrade, Serbia \\ ${ }^{4}$ Institute for Human Rehabilitation, Tuzla, Bosnia and Herzegovina
}

Received: $2021 / 7 / 24$

Accepted: 2021/9/25

\begin{abstract}
Speech detection threshold (SDT) depends on audibility alone, whereas speech recognition threshold (SRT) requires the stimuli to be heard and identified. The aim of the study was to determine the difference between SDT and SRT, and to analyze the correlation between pure tone thresholds and speech thresholds. Difference between SDT and SRT was $\leq 12 d B$ in majority of cases $(p=.018)$. SDT was strongly correlated with the best pure tone threshold. Pearson correlation coefficient was the highest in "Inverted U" shape $(r=.99)$. There was strong correlation between SRT and PTA (500-2000), PTA (500-4000), and PTA (500-1000), especially in Rising configuration ( $r=.997, r=.992 r=.989$, respectively), as well as, between SRT and frequency of $1000 \mathrm{~Hz}(r=.989)$. SRT is in the highest correlation with PTA $(500,1000,2000 \mathrm{~Hz})$ and with the hearing threshold at frequency of $1000 \mathrm{~Hz}$.

Keywords: correlation, hearing threshold, speech threshold
\end{abstract}

\section{INTRODUCTION}

Pure tone audiometry involves finding the lowest sound pressure levels for different pure tones that a person is barely able to hear. The lowest sound pressure level of a pure tone to which a person reliably responds at least $50 \%$ of the time is called a hearing threshold for that frequency (Kramer \& Brown, 2019). Pure tone thresholds are an example of a psychophysical measure relating the physical characteristics of a tone to a behavioral threshold. Conventional pure tone audiometry typically assesses thresholds for frequencies between 250 (or 125) and $8000 \mathrm{~Hz}$ (Schlauch \& Nelson, 2015). An auditory range of the human ear riches up to $20000 \mathrm{~Hz}$. Threshold measurements at extended highfrequencies between 9000 and $20000 \mathrm{~Hz}$ may be useful in early diagnosis of hearing loss in certain conditions (Rodriguez Valiente et al., 2016).
Speech audiometry evaluates a person's ability to hear and understand speech (Shipley \& McAfee, 2016). There are two types of threshold measures using speech stimuli: speech detection threshold (SDT) and speech recognition threshold (SRT). SDT is an estimate of the level at which an individual perceives speech to be present $50 \%$ of the time (McArdle \& HnathChisolm, 2015). SRT is the softest level at which an individual can repeat back spondaic words $50 \%$ of the time (Tye-Murray, 2020). Spondaic words or spondees are two-syllable words with equal stress on both syllables (Bess \& Humes, 2008). The most common suprathreshold measure in quiet is word recognition score (WRS) and is generally measured in percent correct at a level relative to the SRT (Gelfand, 2016).

Correspondence to:

Lidija Ristovska, City General Hospital “8 ${ }^{\text {th }}$ September”, Department of Otorhinolaryngology, Division of Audiology, Skopje

Pariska NN. 1000 Skopje

Tel. +389023087612

E-mail: lidijaristovska@yahoo.com 
There is a relationship between SDT, SRT and pure tone thresholds. The important clinical value of the SDT is that it should agree closely with the best pure tone threshold within the audiometric frequency range (Stach, 2010). The SRT and SDT represent different criteria: intelligibility vs. detectability. Speech can be detected at intensity levels lower than it can be understood, on the order of 8 to $12 \mathrm{~dB}$ (Diefendorf, 2015).

Because speech is used to determine speech thresholds, the thresholds of the pure tone frequencies that are most important for speech understanding should closely match the SRT. Specifically, an average of the pure tone thresholds at 500,1000, and $2000 \mathrm{~Hz}$, known as the pure tone average (PTA) should match the SRT within 7 to $10 \mathrm{~dB}$ (DeRuiter \& Ramachandran, 2017). It is also considered that the SRT is in agreement with the PTA if there is less than $12 \mathrm{~dB}$ difference between these measures (Dutta et al., 2016).

SRTs obtained using spondaic words agree well with pure tone thresholds for low frequencies. Spondees are easily recognized. Listeners only need to recognize the vowels to identify these words correctly. Because of the importance of the vowels at low frequencies, spondee thresholds are found to agree closely with the average of pure tone thresholds for 500 and $1000 \mathrm{~Hz}$. In the case of a rising audiogram, better agreement between the spondee and pure tone thresholds is the average for 1000 and $2000 \mathrm{~Hz}$ (Schlauch \& Nelson, 2015).

The aim of the study was to determine the difference between SDT and SRT, and to analyze the correlation between pure tone thresholds, SDTs and SRTs.

\section{METHODS}

This prospective study included a sample of 110 patients with hearing loss, 50 males and 60 females, aged 5 to 75 years (mean age of $51.2 \pm 19.5$ years), examined at the Department of Otorhinolaryngology, Division of Audiology, City General Hospital " 8 th September" Skopje. Inclusion criteria were: unilateral or bilateral hearing loss, mild, moderate or severe hearing loss. Exclusion criteria were: age under 5 years in children and above 75 in adults, as well as deafness. Pure tone audiometry and speech audiometry were performed with MADSEN Astera ${ }^{2}$ audiometer and Sennheiser HDA 300 (Sennheiser electronic, Germany) circumaural earphones in sound proof booth.
Hearing threshold was obtained with modified Hughson-Westlake technique for frequencies from 125 to $8000 \mathrm{~Hz}$. Normal hearing was defined as thresholds $\leq 20 \mathrm{~dB} \mathrm{HL}$ for frequencies from 250 to $8000 \mathrm{~Hz}$.

Audiometric configuration was defined in the following way:

Rising - hearing threshold at low frequencies is at least $20 \mathrm{~dB}$ poorer than hearing threshold at high frequencies; Sloping - hearing threshold at high frequencies is at least $20 \mathrm{~dB}$ poorer than hearing threshold at low frequencies;

Flat - the difference between the maximum hearing threshold and the minimum hearing threshold is $\leq 20$ $\mathrm{dB}$;

Notch - a sharp drop in the hearing sensitivity at 4000 $\mathrm{Hz}$ of at least $15 \mathrm{~dB}$ in relation to both, the threshold at $2000 \mathrm{~Hz}$ and the threshold at $8000 \mathrm{~Hz}$;

$U$ shape - hearing threshold at $1000 \mathrm{~Hz}$ and/or 2000 $\mathrm{Hz}$ is $20 \mathrm{~dB}$ poorer than hearing threshold at $500 \mathrm{~Hz}$ and threshold at $4000 \mathrm{~Hz}$;

Inverted U shape - hearing threshold at $1000 \mathrm{~Hz}$ and/ or $2000 \mathrm{~Hz}$ is $20 \mathrm{~dB}$ better than hearing threshold at $500 \mathrm{~Hz}$ and threshold at $4000 \mathrm{~Hz}$.

Speech detection threshold, speech recognition threshold, and word recognition score were determined in all patients. Speech audiometry was performed with the recorded speech material: Ristovska and Jachova Monosyllabic Test 1 and Test 2; Ristovska and Jachova Disyllabic Test 3 and Test 4. For statistical data analysis we used Chi-square test, Fisher's exact test and Pearson correlation coefficient with level of significance $p<$ .05 . The study was approved by the Ethics committee of City General Hospital " $8{ }^{\text {th }}$ September" Skopje. The Protocol number of Ethical approval is: 24/89-1/2019.

\section{RESULTS}

Our study included a sample of 110 patients, 12 children (10.9\%), and 98 adults (89.1\%). We displayed demographic and clinical characteristics of patients (Table 1). Unilateral hearing loss was present in 26 patients $(23.6 \%)$, and 84 patients $(76.4 \%)$ had bilateral hearing loss. A total of 220 ears were analyzed. In terms of the degree of hearing loss, mild hearing loss was the most common $(65.5 \%)$. Sensorineural hearing loss was the most common type of hearing loss $(80.4 \%)$.

Table 1. Demographic and clinical characteristics of patients

\begin{tabular}{cc}
\hline Characteristics & No $(\mathbf{\%})$ \\
\hline Age (Years) & \\
$5-14$ & $12(10.9)$ \\
$22-30$ & $6(5.5)$ \\
$31-40$ & $5(4.5)$ \\
$41-50$ & $19(17.3)$ \\
$51-60$ & $24(21.8)$ \\
$61-70$ & $34(30.9)$ \\
$71-75$ & $10(9.1)$ \\
\hline
\end{tabular}


Table 1. Continued

\begin{tabular}{lc}
\hline Characteristics & No $(\%)$ \\
\hline Gender & $50(45.5)$ \\
Male & $60(54.5)$ \\
Female & \\
Side of hearing loss & $10(9.1)$ \\
$\quad$ Unilateral right & $16(14.5)$ \\
Unilateral left & $84(76.4)$ \\
Bilateral & \\
Degree of hearing loss $(220$ ears $)$ & $26(11.8)$ \\
$\quad$ Normal & $144(65.5)$ \\
Mild & $34(15.5)$ \\
Moderate & $16(7.3)$ \\
Severe & \\
Type of hearing loss $(194 \text { ears })^{*}$ & $24(12.4)$ \\
Conductive & $156(80.4)$ \\
Sensorineural & $14(7.2)$ \\
Mixed &
\end{tabular}

*Normal hearing ears were excluded

We determined the difference between SDT and SRT significant difference between the intensity level of in terms of the audiometric configuration (Table 2). speech thresholds and audiometric configuration $\left(\chi^{2}=\right.$ There was a difference $\leq 12 \mathrm{~dB}$ in majority of cases. A $6.578, \mathrm{df}=5, \mathrm{p}=.254$ ).

statistical analysis shows that there is not statistically

Table 2. Difference between SDT and SRT in terms of the audiometric configuration

\begin{tabular}{lcccccc}
\hline $\begin{array}{l}\text { Audiometric } \\
\text { configuration }\end{array}$ & \multicolumn{2}{c}{$\mathbf{1 2} \mathbf{~ d B}$} & \multicolumn{2}{c}{$>\mathbf{1 2} \mathbf{d B}$} & \multicolumn{2}{c}{ Total } \\
\cline { 2 - 7 } & No & $\mathbf{\%}$ & No & $\mathbf{\%}$ & No & \% \\
\hline Rising & 5 & 2.6 & 5 & 2.6 & 10 & 5.2 \\
Sloping & 68 & 35.1 & 27 & 13.9 & 95 & 49 \\
Flat & 31 & 16 & 10 & 5.2 & 41 & 21.1 \\
Notch & 21 & 10.8 & 6 & 3.1 & 27 & 13.9 \\
U shape & 6 & 3.1 & 5 & 2.6 & 11 & 5.7 \\
Inverted U & 5 & 2.6 & 5 & 2.6 & 10 & 5.2 \\
Total & 136 & 70.1 & 58 & 29.9 & 194 & 100 \\
\hline
\end{tabular}

Chi-square test $(\mathrm{p}=.254)$

We also calculated the difference between SDT and SRT in normal hearing ears and cases of hearing loss (Table 3). There was a difference $\leq 12 \mathrm{~dB}$ in majority of cases.
A statistical analysis with Fisher's exact test shows that there is statistically significant difference between the intensity level of speech thresholds and patient's hearing $(\mathrm{p}=.018)$.

Table 3. Difference between SDT and SRT in cases of normal hearing and hearing loss

\begin{tabular}{lcccccc}
\hline Patient's & \multicolumn{2}{c}{$\leq \mathbf{1 2} \mathbf{d B}$} & \multicolumn{2}{c}{$>\mathbf{1 2} \mathbf{d B}$} & \multicolumn{2}{c}{ Total } \\
\cline { 2 - 7 } hearing & No & $\mathbf{\%}$ & No & $\mathbf{\%}$ & No & \% \\
\hline Normal hearing & 24 & 10.9 & 2 & .9 & 26 & 11.8 \\
Hearing loss & 136 & 61.8 & 58 & 26.4 & 194 & 88.2 \\
Total & 160 & 72.7 & 60 & 27.3 & 220 & 100 \\
\hline
\end{tabular}

Fisher's exact test $(\mathrm{p}=.018)$ 
We analyzed the correlation between SDT and hearing thresholds in different audiometric configuration (Table 4).

Table 4. Correlation between SDT and hearing thresholds in different audiometric configuration

\begin{tabular}{lcccccccc}
\hline \multirow{2}{*}{$\begin{array}{l}\text { Audiometric } \\
\text { configuration }\end{array}$} & \multicolumn{2}{c}{ Best threshold } & \multicolumn{2}{c}{ PTA (500-4000) } & \multicolumn{2}{c}{ PTA (500-2000) } & \multicolumn{2}{c}{ PTA (500-1000) } \\
\cline { 2 - 9 } & $\mathbf{r}$ & $\mathbf{p}$ & $\mathbf{r}$ & $\mathbf{p}$ & $\mathbf{r}$ & $\mathbf{p}$ & $\mathbf{r}$ & $\mathbf{p}$ \\
\hline Rising & .987 & $<.00001$ & .978 & $<.00001$ & .976 & $<.00001$ & .966 & $<.00001$ \\
Sloping & .945 & $<.00001$ & .894 & $<.00001$ & .927 & $<.00001$ & .924 & $<.00001$ \\
Flat & .971 & $<.00001$ & .96 & $<.00001$ & .958 & $<.00001$ & .944 & $<.00001$ \\
Notch & .973 & $<.00001$ & .854 & $<.00001$ & .842 & $<.00001$ & .872 & $<.00001$ \\
U shape & .95 & $<.00001$ & .82 & .001978 & .848 & .000976 & .632 & .036965 \\
Inverted U & .99 & $<.00001$ & .923 & $<.00001$ & .967 & $<.00001$ & .949 & .000028 \\
\hline
\end{tabular}

SDT was in the highest correlation with the best pure tone threshold in all types of audiometric configuration. Pearson correlation coefficient was highest in "Inverted U" shape $(\mathrm{r}=.99, \mathrm{p}<.00001)$. Correlation between SRT and PTA in different $=.997, \mathrm{p}<.00001)$.

audiometric configuration was analyzed (Table 5).
SRT was in the highest correlation with PTA at frequencies 500, 1000, and $2000 \mathrm{~Hz}$ in all types of audiometric configuration. Pearson correlation coefficient was the highest in Rising configuration ( $\mathrm{r}$

Table 5. Correlation between SRT and PTA in different audiometric configuration

\begin{tabular}{lcccccc}
\hline $\begin{array}{l}\text { Audiometric } \\
\text { configuration }\end{array}$ & \multicolumn{2}{c}{ PTA (500-4000) } & \multicolumn{2}{c}{ PTA (500-2000) } & \multicolumn{2}{c}{ PTA (500-1000) } \\
\cline { 2 - 7 } & $\mathbf{r}$ & $\mathbf{p}$ & $\mathbf{r}$ & $\mathbf{p}$ & $\mathbf{r}$ & $\mathbf{p}$ \\
\hline Rising & .992 & $<.00001$ & .997 & $<.00001$ & .989 & $<.00001$ \\
Sloping & .947 & $<.00001$ & .97 & $<.00001$ & .957 & $<.00001$ \\
Flat & .975 & $<.00001$ & .976 & $<.00001$ & .97 & $<.00001$ \\
Notch & .94 & $<.00001$ & .962 & $<.00001$ & .951 & $<.00001$ \\
U shape & .91 & .000109 & .945 & .000012 & .662 & .026394 \\
Inverted U & .969 & $<.00001$ & .981 & $<.00001$ & .951 & .000023 \\
\hline
\end{tabular}

We analyzed correlation between SRT and hearing thresholds for speech frequencies 500, 1000, 2000, and $4000 \mathrm{~Hz}$ in different audiometric configuration (Table 5).
SRT was in the highest correlation with hearing threshold at frequency of $1000 \mathrm{~Hz}$ in all types of audiometric configuration. Pearson correlation coefficient was the highest in Rising configuration $(r=.989, \mathrm{p}<.00001)$.

Table 6. Correlation between SRT and hearing threshold for speech frequencies

\begin{tabular}{lccccccccc}
\hline \multirow{2}{*}{$\begin{array}{l}\text { Audiometric } \\
\text { configuration }\end{array}$} & \multicolumn{3}{c}{$\mathbf{5 0 0}$} & \multicolumn{2}{c}{$\mathbf{1 0 0 0}$} & \multicolumn{2}{c}{$\mathbf{2 0 0 0}$} & \multicolumn{4}{c}{$\mathbf{4 0 0 0}$} \\
\cline { 2 - 10 } & $\mathbf{r}$ & $\mathbf{p}$ & $\mathbf{r}$ & $\mathbf{p}$ & $\mathbf{r}$ & $\mathbf{p}$ & $\mathbf{r}$ & $\mathbf{p}$ \\
\hline Rising & .987 & $<.00001$ & .989 & $<.00001$ & .988 & $<.00001$ & .869 & .00109 \\
Sloping & .933 & $<.00001$ & .951 & $<.00001$ & .937 & $<.00001$ & .712 & $<.00001$ \\
Flat & .964 & $<.00001$ & .969 & $<.00001$ & .961 & $<.00001$ & .911 & $<.00001$ \\
Notch & .916 & $<.00001$ & .961 & $<.00001$ & .91 & $<.00001$ & .712 & .000032 \\
U shape & .499 & .118245 & .754 & .007373 & .725 & .011606 & .621 & .041568 \\
Inverted U & .923 & .00014 & .95 & .000026 & .944 & .000039 & .855 & .001609 \\
\hline
\end{tabular}

Speech recognition threshold was the starting point for word recognition score. In Figure 1 we displayed tonal and speech audiogram of patient with conductive hearing loss in the left ear.
In this case, SDT was $30 \mathrm{~dB} \mathrm{HL}$, the same level as the best pure tone thresholds (frequency of 2000 and $4000 \mathrm{~Hz}$ ). SRT was $36 \mathrm{~dB} \mathrm{HL}$. 
Speech audiogram shows a psychometric function of word recognition performance as a function of percent correct (ordinate) and presentation level (abscissa).
The curve in conductive hearing loss has the same shape as curve in normal hearing ear with WRS 100\%, but it is obtained at higher intensity levels.
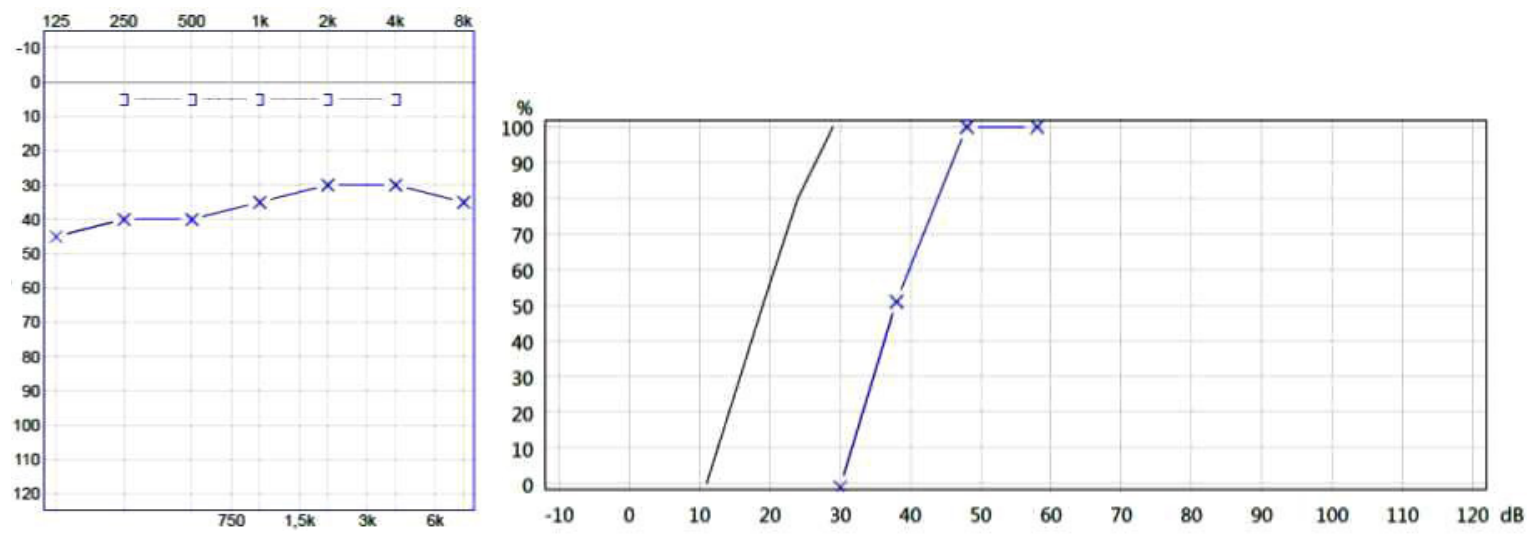

Figure 1. Tonal and speech audiogram of patient with conductive hearing loss

In Figure 2 we displayed tonal and speech audiogram of patient with sensorineural hearing loss in the left ear.
In this case, maximal WRS is $78 \%$ and the curve is typical for cochlear hearing loss.
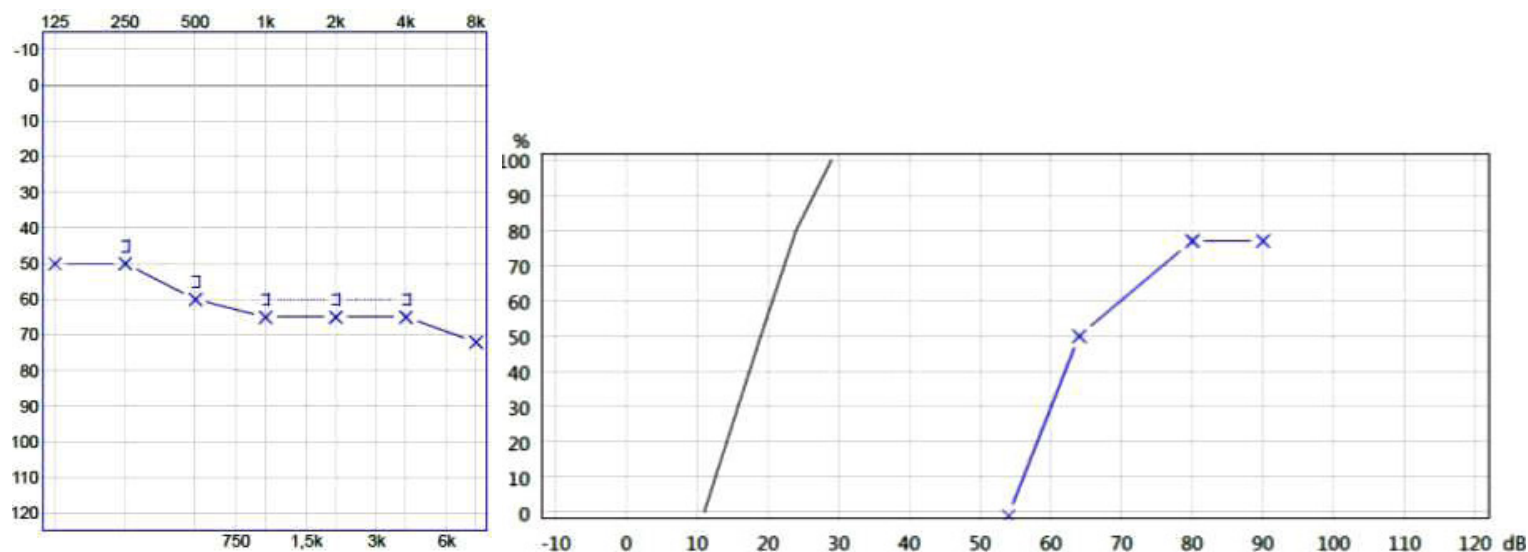

Figure 2. Tonal and speech audiogram of patient with sensorineural hearing loss

\section{DISCUSSION}

We determined the difference between SDT and SRT in terms of the audiometric configuration, and difference between speech thresholds related to presence of hearing loss. There was a difference $\leq 12 \mathrm{~dB}$ in majority of cases. SDT is lower because it depends on audibility alone, whereas SRT requires the stimuli to be heard and identified (Gelfand, 2016).

We analyzed the correlation between pure tone thresholds, SDTs, and SRTs in patients with hearing loss. There was the highest correlation between SDT and the best hearing threshold in all types of audiometric configuration. When using the SDT as a cross-check with the PTA, we must consider whether there is good agreement with the best pure tone threshold between 250 and $4000 \mathrm{~Hz}$ (Kramer \& Brown, 2019).

In our study there was the highest correlation between SRT and PTA calculated at frequencies 500, 1000, and $2000 \mathrm{~Hz}$. The SRT is normally $10 \mathrm{~dB}$ higher than PTA at 500,1000 , and $2000 \mathrm{~Hz}$ of the corresponding audiogram.
A difference of more than $10 \mathrm{~dB}$ raises questions about test reliability and pseudohypoacusis (Hamid \& Brookler, 2006). Kim et al. (2016) explored the relationship between the SRT and several variations of PTA. They found high correlation between SRT and PTA calculated at frequencies 500, 1000, and $2000 \mathrm{~Hz}$. The addition of frequencies higher than $2000 \mathrm{~Hz}$ to a PTA formula seems to have impeded the PTA-SRT agreement, especially for high-frequency steeply sloping audiograms.

Variance from the best SRT-PTA $(500,1000,2000)$ agreement can be seen in pseudohypoacusis or in steeply sloping hearing loses where the SRT may be closer to the best tones in the PTA than the average of 500, 1000, and $2000 \mathrm{~Hz}$ (Babu, 2013). According to Gelfand (2016) adequate speech recognition actually depends on a much wide range of frequencies. Moreover, this three-frequency average often fails to agree with the SRT, especially when the shape of the pure tone audiogram slopes sharply. 
Under these circumstances SRT is in higher correlation with the two-frequency pure tone average, usually 500 and $1000 \mathrm{~Hz}$ (Gelfand, 2016). If the PTA and the speech thresholds do not correlate well, it is important to consider the possibility of malingering or central auditory dysfunction. If the speech thresholds are much better than the PTA, pseudohypoacusis should be considered. If the PTA is significantly better than the speech thresholds, the possibility of central involvement should be considered (Squires, Colombo \& McKinney, 2019).

There was high correlation between SRT and PTA at $500,1000,2000$, and $4000 \mathrm{~Hz}$ in our study. Some authors found the highest correlation between SRT and PTA at more than three frequencies. In cases of rising and sloping audiometric configuration in patients with sensorineural hearing loss, de Andrade et al. (2013) concluded that frequencies 500,1000, 2000, and 4000 $\mathrm{Hz}$ were most significant for predicting the SRT. Maeda et al. (2018) found high correlation between SRT and PTA calculated at all frequencies tested $(125,250,500$, 1000, 2000, 4000, and $8000 \mathrm{~Hz}$ ).

When we compared the SRT separately with speech frequencies $500,1000,2000$, and $4000 \mathrm{~Hz}$, we found the highest correlation between SRT and frequency of 1000 Hz. Chien et al. (2006) found the highest correlation between SRT and frequency of $1000 \mathrm{~Hz}$, followed by 500,250 , and $2000 \mathrm{~Hz}$. The highest correlation between SRT and frequency of $1000 \mathrm{~Hz}$ was found in cases of sloping audiometric configuration (dos Anjos et al., 2014). We found the highest correlation between SRT and frequency of $1000 \mathrm{~Hz}$ in all audiometric configurations.

\section{CONCLUSION}

Speech detection threshold is in the highest correlation with the best pure tone threshold. Speech recognition threshold is in the highest correlation with the pure tone average at frequencies of 500, 1000, and 2000 $\mathrm{Hz}$, as well as, with the hearing threshold at frequency of $1000 \mathrm{~Hz}$. The well-known agreement between pure tone thresholds and speech recognition thresholds makes the speech thresholds an excellent check on the reliability of the audiogram.

\section{REFERENCES}

Babu, S. (2013). Practical otology for the otolaryngologist. San Diego: Plural Publishing.

Bess, F.H., \& Humes, L.E. (2008). Audiology: The fundamentals. Philadelphia: Lippincott Williams \& Wilkins.

Chien, C.-H., Tu, T.-Y., Chien, S.-F., Li, A.C.-I., Yang, M.-J., Shiao, A.-S., \& Wang, Y.-F. (2006). Relationship between Mandarin speech reception thresholds and pure-tone thresholds in the geriatric population. Journal of the Formosan Medical Association, 105(10), 832-838. doi. org/10.1016/S0929-6646(09)60270-9 de Andrade, K.C.L., de Lemos Menezes, P., Carnaúba, A.T.L., de Sousa Rodrigues, R.G., de Carvalho Leal, M., \& Pereira, L.D. (2013). Non-flat audiograms in sensorineural hearing loss and speech perception. Clinics (Sao Paulo), 68(6), 815-819. doi.org/10.6061/clinics/2013(06)15

DeRuiter, M., \& Ramachandran, V. (2017). Basic audiometry learning manual. $2^{\text {nd }}$ ed. San Diego: Plural Publishing.

Diefendorf, A.O. (2015). Assessment of hearing loss in children. In: J. Katz, M. Chasin, K. English, L.J. Hood \& K.L. Tillery, eds. (2015). Handbook of clinical audiology. Philadelphia: Lippincott Williams \& Wilkins. Ch.24.

dos Anjos, W.T., Labanca, L., de Resende, L.M., \& CostaGuarisco, L.P. (2014). Correlation between the hearing loss classifications and speech recognition. Revista CEFAC, 16(4), 1109-1116. doi.org/10.1590/1982-0216201423512

Dutta, A., Chatterjee, I., Khemka, S., Chatterjee Shahi, A., \& Ghosh, P. (2016). Development and standardization of spondee words in Bangla. Asia Pacific Journal of Research, $1(38), 14-18$.

Gelfand, S.A. (2016). Essentials of audiology. New York: Thieme Medical Publishers.

Hamid, M.A., \& Brookler, K.H. (2006). Speech audiometry. ENT-Ear, Nose \& Throat Journal, 85(12), 810-812. doi. org/10.1177/014556130608501207

Kim, J.M., Na, M.S., Jung, K.H., Lee, S.H., Han, J.S., Lee, O.H., \& Park, S.Y. (2016). The best-matched pure tone average and speech recognition threshold for different audiometric configurations. Korean Journal of OtorhinolaryngologyHead and Neck Surgery, 59(10), 725-729. doi.org/10.3342/ kjorl-hns.2016.59.10.725

Kramer, S., \& Brown, D.K. (2019). Audiology: science to practice. $3^{\text {rd }}$ ed. San Diego: Plural Publishing, Inc.

Maeda, Y., Takao, S., Sugaya, A., Kataoka, Y., Kariya, S., Tanaka, S., Nagayasu, R., Nakagawa, A., \& Nishizaki, K. (2018). Relationship between pure-tone audiogram findings and speech perception among older Japanese persons. Acta Oto-Laryngologica, 138(2), 140-144. doi: 10.1080/00016489.2017.1378435.

McArdle, R., \& Hnath-Chisolm, T. (2015). Speech audiometry. In: J. Katz, M. Chasin, K. English, L.J. Hood \& K.L. Tillery, eds. (2015). Handbook of clinical audiology. Philadelphia: Lippincott Williams \& Wilkins. Ch.5.

Rodriguez Valiente, A., Roldán Fidalgo, A., Villarreal, I.M., \& García Berrocal, J.R. (2016). Extended high-frequency audiometry $(9000-20000 \mathrm{~Hz})$. Usefulness in audiological diagnosis. Acta Otorrinolaringologica Espanola, 67(1), 40-44.

Schlauch R.S., \& Nelson, P. (2015). Puretone evaluation. In J. Katz, M. Chasin, K. English, L.J. Hood \& K.L. Tillery, eds. (2015). Handbook of clinical audiology. Philadelphia: Lippincott Williams \& Wilkins. Ch.3.

Shipley, K.G., \& McAfee, J.G. (2016). Assessment in speechlanguage pathology, A resource manual. $5^{\text {th }}$ ed. Boston: Cengage Learning.

Squires, L.D., Colombo, B.A., \& McKinney, S. (2019). Rapid audiogram interpretation: a clinician's manual. San Diego: Plural Publishing.

Stach, B.A. (2010). Clinical audiology: an introduction. Clifton Park: Delmar Cengage Learning.

Tye-Murray, N. (2020). Fondations of aural rehabilitation: children, adults, and their family members. $5^{\text {th }}$ ed. Sun Diego: Plural Publishing. 